\title{
Use of Conventional Teaching Resources in Secondary Schools in Bungoma County, Kenya
}

\author{
Patrick Makari \\ Kibabii University \\ Faculty of Education \& Social Sciences \\ PO Box 1699-50200 Bungoma \\ Stanley Ngome Mutsotso \\ Faculty of Education \& Social Sciences \\ Kibabii University \\ P.O Box 1699-50200 \\ Edwin Masibo \\ Faculty of Education \& Social Sciences \\ Kibabii University \\ P.O Box 1699-50200
}

\begin{abstract}
Education is core to national development as it provides the human resource and intellectual capital to drive economies. Attaining this hence requires meaningful and gainful learning through the incorporation of a range of instructional resources that help develop learners skills, attitudes and practical competencies required in the ever changing market economy. However, in spite of the various government interventions to increase access to education, empirical research evidence shows that students continue to perform dismally in both formative and summative evaluation. The paper therefore sought to determine the dynamics existing in the utilization of conventional teaching resources in secondary schools in Bungoma County. The paper was guided by the Cognitive Theory of Instructional as propounded by Jean Piaget that emphasizes the significance of instructional resources in the teaching and learning process. The paper adopted a descriptive survey design. The target population consisted of teachers and students from public secondary schools in Bungoma County. In order to have a representative sample, this paper employed stratified random sampling to select schools. Questionnaires, interview and observation schedules and document analysis were used as data collection instruments. Validity was established through expert opinion. Reliability was established through piloting. Data was analyzed using inferential and descriptive statistics. The findings showed that majority of teachers, students and principals were of the opinion that public secondary schools in Bungoma County had inadequate conventional instructional resources. It was further deduced that funding, number of students and teachers' ease of use influenced the acquisition of conventional instructional resources in public secondary schools in Bungoma County. From the findings it was recommended that educational stakeholders should improve the quality of instructional through proper identification, selection and utilization of instructional resources. There is need for all stakeholders including the County Government, National Government and the Private sector to contribute financially and materially in the provision of conventional instructional materials and resources.
\end{abstract}

Keywords:Convectional, education, teaching resources, teaching resources, utilization,

DOI: $10.7176 /$ RHSS/9-22-06

Publication date: November $30^{\text {th }} 2019$

\section{Introduction}

Education consists of two major components namely inputs and outputs. (Coombs, 1970). The researcher further states that inputs are human and material resources and that outputs are the goals and outcomes of the educational process. The study showed that the inputs and outputs formed an organic dynamic whole and that for any successful study on assess and improvement of the educational system one needs to investigate on the two components as each component affect the other.

Conventional instructional resources, physical facilities and human resources are often mostly underfunded by the government. Therefore in many countries it has been a problem facing the levels of literacy as both teachers and learner lack what to read as little is provided for by the government (The World Bank, 2001). It can be observed that availability of both material and physical resources directly influence not only educational attainment of students by also teacher and student motivation and thus the educational outcomes.

According to Adeyemi and Adu (2010) education is regarded as one of the main instrument for influencing socio-economic developments of any country as it entails processes and procedures that individuals go through to help them develop and realize their full potentials. The study by Okeke (2007) further indicated that, through 
basic education, individuals acquire the right attitudes, skills and competencies needed in live for effective living. This rationalizes why developed states invest heavily in the education of the youth who are critical in socioeconomic transformation of the nation. However a study by Onsomu et, al, (2006), opined that in the preparation of human capital for nations, both primary and secondary education systems are significant for economic development as they provide opportunities through basic education, further training and the world of work. The quality of education was manifested through literary cognitive abilities, progress to higher levels of learning and academic achievement. However, quality education cannot be achieved without educational resources which play an important role in the achievement of educational goals and objectives. Adeogun and Ofisila (2008) however observed that there are four categorizes of educational conventional resources that is materials, financial, human and physical resources. Conventional instructional resources as opined by Usman (2007) are central to the educational achievement because of the important role they play in the achievement of educational objectives and goals as they facilitate teachers' preparations and subj ect delivery as well as accelerating learning process on the part of the student.

According to Hoop (2010) educational systems in countries in Sub-Saharan Africa faced chronic deficiency in the acquisition of conventional instructional resources. He further noted that rather than equally disbursing instruction resources to all schools, many governments unfairly distributes them with some schools accessing more at the expense of other deserving schools. According to the findings by World Bank (2008) in a study on disbursement of conventional instructional resources in public secondary schools in countries in sub-Saharan African such as Botswana, Cameroon, Coted'vore, Ghana, , Rwanda, Tanzania, Kenya, Malawi and Togo found the imbalance in distribution with urban schools getting more materials as compared to similar schools in the rural setups. However, an earlier study by Fabunmi (1997) backed the study findings by indicating that in Edo state in Nigeria there was a common feature of difference in distribution and allocation of facilities to schools.

Selection of resources generally depends on where and under what conditions the materials will be experienced by students. Otunga (2010) noted that, instructional resources exist in two forms; the human resources and the non-human resources. The non-human resources comprise of teaching materials, which are considered in two major categories, the textual (print) and the non-textual (non-print) materials. Most literature on teaching resources focuses generally on print resources such as teaching reference books and journal articles, (Schonwetter, 2008). Mukwa (2002) argues that teaching and instructional resources exist in many forms; multimedia presentations, teaching websites and repositories, government sites, CDs and films. Pollard (2002) in his classification of instructional resources, identified four categories that are essential in education namely people, buildings, equipment and materials concentration. The quality elements that have been found to be consistently related to achievement are: desks, instructional materials, especially text books, school library, teacher quality, lying of instructional programmes and school administration. Others are frequency of pupil's school attendance, exercise books, and use of instructional radio and in service teacher training (Eshiwani, 1993). The improvement of educational quality is dependent on instructional material per pupil.

Instructional resources enrich, support and help implementation of educational programmes in schools by fostering an interaction between teachers, educational stakeholders and other members of the community. It was therefore the duty of educational stakeholders to provide students with a wide range of conventional instructional resources at varying levels of diversity of appeal and the presentation of different points of view (MOEST, 2004). Thus it is the responsibility of educational stakeholders to provide the learners with educational materials that can enrich and support the educational outcomes of the learners by taking into consideration the varied interests of learners, their abilities, their learning styles and their maturity levels.

Alubisia (2005) concluded that it was in agreement that the schools in undeveloped and developing countries need more qualified and adequate teachers, more current textbooks and materials, better and spacious classrooms and other teacher related in-puts. But when funding for educational systems is constrained sourcing for the said facilities would be impossible to attain. The rapid expansion of primary and secondary schools necessitated the demand for more buildings, equipment and teachers. It means that more funds should be allocated for these needs. But there is shortage of funds which does not meet the requirements of rapid expansion of secondary schools. This has led to lack of teachers and facilities (Nyongesa, 2007). The result is that the rising number of students in every school placed a heavy burden on limited teaching staff. He further noted that many students in these schools dropped out or repeated a class. The limited school facilities were poor and did not adequately meet the needs and standards of students.

The Kenyan government commitment to attain millennium development goals by 2030 required substantial and long term increase in the provision of teaching and instructional resources. These mean adoption of measures that argument national budget by partnering with the private sector in the funding of education. Increased enrollment in secondary schools owing to subsidized education program has strained available infrastructural facilities, increase students teacher ratio, text books student ratio and caused congestion in schools.

The problem of lack of enough physical facilities in schools is experienced in the post-independence era, for example urban schools until recently have been better equipped than rural ones. The harambee secondary 
schools were up to 2000 still poorly equipped. The facilities especially libraries, laboratories, furniture and text books in most institutions are inadequate. Some institutional buildings were in a rotten state due to poor maintenance and poor conditions (Daily Nation; July 6, 1996, Pg. 5).

In the sessional paper No. 1 of 2005, indicated that the Kenya government made a commitment to increase access to education and attain millennium development goals by 2030 . To realize this goal, the government undertook various strategies and was implementing reforms to address emerging challenges. It was indicated since the growth of secondary education does not match that of primary schools this has been a constraining factor for the expansion of secondary education. For example in 2003, there were more primary schools 18,018 as compared to 3,661 public secondary schools and 641 registered private secondary schools (MOEST, 2009). The demand was more secondary education was much more in urban areas with more slums and with an average 60 percent of the total population was concentrated. It was noted that factors such high cost of secondary education in terms of fees, high prices of conventional instructional resources, ravaging poverty, higher costs of school uniforms, poor transport networks and development levies, and extra expenses for private tuition, unfriendly environment, and negative effects of HIV/AIDS pandemic and rising repetition rates has seen a decline in secondary school enrollment over the last decade (UNESCO, 2008). As observed by (Sifuna, 2003) the existing facilities in many secondary schools make a mockery of free education program that is a setback to good performance. With the ban on school levies many schools boards of management felt that improving the state of conventional instructional resources in schools would be hard to be attained. For example during first term and second term 2010, failure by the government to release funds on time led to many schools incurring huge debts. This hindered effective acquisition and distribution of teaching and instructional resources needed in schools.

Utilization and provision of material resources is the responsibility of all the educational stakeholders in the country (National Policy on Education, 2012). The government Kenya has been in the process of ensuring that the national educational policy is fully implemented by providing an enabling environment. Parents on the hand should be involved in purchase of conventional instructional resources for their schools and also in ensuring that Parents Teachers Association participates in constructing more physical facilities through what is commonly known as referred to is Parents Teachers Association (PTA) projects. With the emergency of FSE, the government of Kenya has experienced challenges with adequate provision of conventional instructional resources in public schools. The report by Kamunge (1988) opined that the construction of public day secondary schools as a way of expanding quality day secondary education, despite all government efforts, planning and provision for conventional instructional resources has remained a challenge in today's FSE with low learning outcomes over the years. This paper therefore sought to determine the dynamics existing in the utilization of conventional teaching resources in secondary schools in Bungoma County.

\subsection{METHODOLOGY}

The paper deployed descriptive survey design and the study was conducted in public Secondary schools in Bungoma County. The county has a total of 231 county and extra county secondary schools with a population of 9,884 school teachers both and 228,188 students The inhabitants of the county value education highly and have invested in it to very great deal. The performance of secondary schools in Bungoma County is above average in Kenya Certificate of Secondary Education examinations.

The target population for this study was students and teachers in national, extra-county, county and sub county secondary schools in Bungoma County. However national schools did not take part in the study since they were adequately equipped and were performing well in academic. Stratified and simple random sampling was employed to sample the 911 respondents. Descriptive and inferential data was collected by use of questionnaires, interview and observation schedules and then analyzed using SPSS

\subsubsection{RESULTS AND DISCUSSIONS}

The score of 1 was assigned very rarely, 2 rarely, 3 moderate, 4 highly and 5 very highly. The average mean score for utilization of resources was determined by adding the minimum score to minimum score and dividing by two. This yielded an average mean of 3 and the findings for utilization of each resource are presented in Table 1 . 
Table 1 Teachers Utilization of Conventional instructional resources

\begin{tabular}{llll}
\hline Utilization Criteria & $\mathbf{N}$ & Mean & Std. Deviation \\
\cline { 2 - 3 } Use of library in teaching & 200 & 1.7800 & .89195 \\
Laboratory use & 200 & 1.6800 & .82523 \\
Use of text books & 200 & 1.6250 & .66073 \\
Use of teaching guides & 200 & 1.6600 & .79217 \\
Use of discussion & 200 & 1.8350 & .88413 \\
Use of teaching Aids & 200 & 1.6250 & .73967 \\
Use of charts & 200 & 1.6600 & .79217 \\
Use of computers & 200 & 1.8400 & .89353 \\
Use of resource Persons & 200 & 1.7600 & .77809 \\
Use of academic trips & 200 & 1.8500 & .91195 \\
Use of the internet & 200 & 2.0500 & 1.02604 \\
Group Teaching & 200 & 1.6600 & .79217 \\
Valid N (list wise) & 200 & & \\
\hline Source: Fid Data & & &
\end{tabular}

\section{Source: Field Data 2016}

From table 1, it can be deduced that the average mean for the study was 3 as derived from the minimum mean of 1.00 and the maximum mean of 4.00 respectively. Based on this finding it was revealed with a mean of 1.78 and standard deviation of 0.89195 that the bulk of teachers showed that the utilization of the library in enhancement of students' classroom performance was below the average mean of 3 . Therefore libraries in the study schools were underutilized to improve the academic performance in public secondary schools under study. This could be interpreted to infer that when school libraries are effectively utilized in the teaching learning processes, academic performance could be improved. Indeed school libraries are one of the school-based quality factors that have to be reckoned with students' academic performance. However the library user statistics from the documentary review showed that more female teachers than their male counterparts used the library materials in lesson preparation and hence were more likely to boost students' classroom performance. Documentary review also showed that libraries were utilized by teachers and students by borrowing books, holding English language lessons and storing old books. As noted from the above findings, majority of schools do not have libraries which hindered utilization. Further those with libraries utilization was hampered by meager reading materials as observed by the researcher. Adeogun (2001) showed a strong relationship and positive significant between instructional materials and performance in academics. Thus according to findings by Adeogun, learning institutions endowed with adequate facilities performed much better than institutions that have little or less facilities. The findings by Adeogun were corroborated the study findings by Babayomi (1999) who opined that private institutions performed much better than public institutions because of the adequacy and availability of learning and teaching resources. A study by Mwiria (1985) also asserted that students' performance was affected by the quantity and quality of learning and teaching resources. The author further asserted that schools with adequate resources such as teaching and learning textbooks tend perform well in national examination than poorly equipped institutions. Therefore, poor academic performance could be as a result of inadequate learning and teaching resources and equipment.

Similarly Adeyemi and Adu (2010), widely opined that education was one of the leading tools for promoting economic growth and development as it includes many processes that learners go through and thus help learners to develop, adopt and utilize their individual potentials. It was also noted by Okeke (2007) in his study that, from education, learners acquire competencies, skills knowledge, and attitudes that are a necessity for better living. On the other hand Onsonu et al (2006), asserted that the foundation of the educational system is secondary education that provide an important link between the world of work and basic education and further training. However Usman (2007) opined that the main foundation to educational processes is educational materials that play an important role in the educational objectives and goals achievement by enhancing efficient and effective learning and teaching. Nonetheless, the study found that even with improvisation, students sparingly borrowed the materials from the mentioned rooms as most of them were outdated. According to Farombi(1998), Libraries in school could not be effective if textbooks there in are not in the right quantity and 
that are currents as its effect might only be useful if the library could be opened to learners always for a considerable length of time in a school day.

The analyzed data also revealed that respondents also agreed with a mean of 1.68 and standard deviation of 0.82523 , which was below the average mean of 3 that the utilization of school laboratories in public secondary schools in Bungoma County was below average. However the study found out that laboratories were utilized for science lessons and carrying out practical's in all categories of schools. However, 2 teachers $(13.3 \%)$ indicated that laboratories were also utilized as classrooms for optional subjects due to inadequate class rooms. The above assessment by teachers was also confirmed by the majority HODs sciences who pointed out those laboratories were utilized for science lessons and for carrying out practical. The adequacy and use of educational resources like laboratories enhance the effectiveness of a teachers' lesson and understanding of abstract ideas and improved performance the reason why their importance cannot be overemphasized. According to Kitheka (2005), one of the main objectives of teaching biology and chemistry is to enhance keen observation for identification of living things and the development of skills to handle chemicals respectively. Further, he noted that it is necessary for students to handle laboratory equipment regularly and adequate time should be given to students to learn the technique of using equipment and developing skills for practical activities. From the above observation one can hypothesis that for students to perform well in science subjects they must regularly participate in carry out experiments in the laboratories. According to the majority of teachers, factors hindering effective utilization of laboratories included poor biology and chemistry laboratory condition status, inadequate staffing, problem of large classes, non-availability of laboratory materials /reagent among others. According to Ologe and Shittu (2011), contemporary chemistry and Biology laboratories must possess the following features a fairly large room with demonstration or preparatory room, and the stores, long tables containing sinks , 4 way type of gas points , 2 tailed reagent shelves water supply taps and drawers. Gas chamber, fume cupboard, refrigerator and air conditioners raised platform safety devices. As observed by the researcher, most of the laboratories especially in mixed day secondary schools fall short of this standard which may have hindered effective utilization hence the dismal performance in science subjects. On relationship between educational resources and students' academic performance Idiage (2004) opined that teacher's qualification and adequate facilities were determinants of assessing academic performance of students in secondary schools. Hence the availability of facilities in schools affects the academic performance of students. Many studies done on factors influencing poor performance of students in KCSE examinations have opined that inadequate teaching learning resources as one of the key variables Kembui (1995), kitheka (2005). Goal attainment in any school depends on adequate supply and utilization of educational resources which enhance proper teaching and learning process within a conducive environment. This could therefore justify the average performance in the boys and girls boarding schools despite their laboratories being relatively fairly equipped.

The data also indicated that majority of respondents with a mean of 1.625 and standard deviation of 0.66073 asserted the utilization of text books in enhancement of students' classroom performance was below average and therefore for effective teaching and learning, text books are basic tools, their absence or inadequacy makes teachers handle subjects in an abstract manner, portraying dry and non-exciting teaching/learning process. However documentary review showed that utilized text books in several ways. Firstly, teachers use text books in preparation of lessons and further references in order to follow up syllabus expectations. Secondly, teachers used text books in giving assignments to students such as making notes and classroom exercises and homework. Further, teachers utilized text books in extracting continuous assessment tests and examinations. The study therefore conforms with Chiriswa (2002) on the study on investigation into the KCSE in Vihiga District who found that textbooks were the common resource used in teaching and learning process and being inadequate may have contributed to poor performance in secondary schools among other factors.

The analyzed data further revealed that most of the teachers cited with a mean of 1.66 and standard deviation of 0.79217 that the utilization of teachers' guides for effective teaching/learning was below average. The interpretation infers that teachers guides themselves are not self-enacting, and that they should be utilized effectively for proper syllabus coverage and subject delivery. The qualitative data obtained from the documentary review supports the study findings when it showed that utilization of teachers' guides was mainly undertaken by the newly employed teachers and those who have not taught for more than 10 years. Just like the utilization of text books, fewer teachers with a teaching experience of over 10 years hardly used the teaching guides thus compromising the state of teaching with the assumption that their many years of teaching had led them into the mastery of the subject content which leaves the students in tire need for knowledge acquisition.

The analyzed data further showed that majority of teachers agreed with a mean of 1.835 and standard deviation of 0.88413 that group discussion in the study schools was underutilized. Therefore effective group discussions could lead to improvement in students' performance. Group discussions can be described by the relationships and interactions between teachers, students, materials and learners' environment. Group discussions therefore are not something done by the teacher to students but rather a process in which knowledge is collectively and collaboratively built through and with classroom resources. 
The data also indicated that respondents agreed with a mean of 1.625 and standard deviation of 0.79217 that teaching aids were underutilized in public secondary schools as it was below the average mean of 3 . This could be inferred to suggest that effective use of teaching aids could lead to effective lesson presentation and delivery and hence improve on students' academic performance. The study by Grubb (2008) argued that a reduction in class size and teachers' underutilization of teaching aids, positive learning out comes were not likely to change. There will be need for compound resources and modified instructional strategies backed by enough relevant teaching aids for effective lesson delivery. The respondents also agreed with a mean of 1.66 and standard deviation of 0.79217 that employment of charts as a teaching/learning resource was also below the average mean of 3 . Therefore a unit increase in the utilization of charts as a teaching learning resource could lead to an increase in students' classroom performance. There is need for a deeper understanding of school dynamics and the way resources are utilized and even created in the schools and the classroom context. According to Eshiwani, (2001), instructional resources in learning and teaching make learners to learn and retain more what they could have been taught and that it also promoted and sustained students' motivation. It also allowed the students to discover themselves and their own abilities and as a consequent provide them with opportunities to realize their full potentials.

The analyzed data further showed that the bulk of teachers with a mean of 1.84 and standard deviation of 0.89353 asserted that teachers had underutilized computers as an instructional resource in public secondary schools in Bungoma County as the mean obtained was below the average mean of 3 . These findings can be inferred to suggest that if computers were effectively utilized in the study schools, they could lead to improvement in students' classroom performance. Therefore teaching at any learning level required that the learner be exposed to various forms of simulations. Computers will give students the opportunity to learn through different senses at one given time, they could learn easier and faster. Therefore the usage of computers will provide the trainer with compelling and interesting platforms for passing information since they motivates pupils to learn even more. It was however asserted that more teachers aged between the 30 to 40 years embraced the use of computers in the teaching learning processes as compared with their counterparts aged above 40 years as obtained from the documentary and observation schedules in the study schools. On average more than $90 \%$ of teachers aged between 30 to 40 years utilized the available computers to enhance students' classroom performance. The dismal use of computers by teachers aged above 40 years may be attributed to the fact that these rooms for computer were poorly equipped and therefore trainers with more training experiences may find them to have little usefulness in improving the mode of delivery of lessons. Again most institutions have put more priority in acquisition of set books, textbooks and teachers' teaching guides at the expense of other instructional materials.

The data captured also indicated that respondents were in agreement with a mean of 1.76 and standard deviation of 0.77809 that the use of resource persons as an instructional resource in public secondary schools in Bungoma County was below the average mean of 3 respectively. It was revealed from the documentary reviews that old and more experienced teachers embraced the usage of resources persons as instructional resources through team teaching as compared with their young colleagues who seem challenged on the use resources persons whom they viewed with suspicion as competitors. The application of instructional materials in education brings about successful learning outcomes since instructional materials stimulate student acquisition of skills as well as motivating their interests. The most common method of examining the application of education materials is examined through school expenditures. This was because individual school expenditures constituted the bulk of all resources afforded to learning and they are tractable tools of education policies (Meghir, 2002).

The analysis further showed that teachers agreed with a mean of 1.85 and standard deviation 0.91195 that the use of use of academic trips as a conventional instructional resource in the study schools was inadequate. This could be interpreted to infer that academic trips if effectively planned and utilized could improve students' classroom performance. The study opined that the use of academic trips mediated instructional to duplicate the traditional face to face classroom has resulted in a shift to the students. The teacher facilities the learning by acting as a coach, resource guide and companion in learning and therefore this could lead to more mastery of subject content and overall classroom performance. Documentary review showed more male teachers as compared to their female counterparts preferred the use of field trips as a conventional instructional resource. It was also showed that more teachers aged below 40 years embraced the usage of field trips as compared to teachers aged above 40 years who however teach similar subject areas as evidenced from the documents reviewed on academic trips. This could be partly due to the fact that most schools do not have buses; hence excursions would entail hiring some means of transport which would be too expensive. The high cost of fuel witnessed in the past few years is also making travelling expensive even for those schools that own buses or vans. Excursions and field trips involve a lot of time in terms of preparation and actual study which may interfere with the formal school timetable. Excursions and field trips enhance

The analyzed data also enlisted that majority of teachers were in agreement with a mean of 2.05 and standard deviation of 1.02604 that the utilization of the internet as a teaching/learning resource was below the 
average mean usage of 3 and therefore most schools should be linked with the internet network to spur the use of the internet in the teaching/learning processes in public secondary schools in Bungoma County. These teachers' responses indicate that there was minimal use of these facilities. This implies that text books are widely used in teaching and learning in FDSS. Therefore for the students to interact with meaningful internet content, they should rely on their teachers to make internet content accessible. Therefore for the internet instructional resource to survive in the classroom climate, the teacher has to recognize the effectiveness of the internet instructional in the classroom and academic performance. However documentary review showed that more young teachers aged below 40 years supplemented their teaching/learning process by integrating internet usage which enabled the students to undertake e-learning and this facilitates accessing information on e-book libraries.

Lastly the analyzed data revealed that the bulk of teachers agreed that group teaching was underutilized as a conventional instructional resource in the study schools as indicated with a mean of 1.66 and standard deviation of 0.79217 which was below the average mean of 3 respectively. Therefore a unit increase in the utilization of group teaching could lead to an improvement in the students' classroom performance.

Therefore based on the analysis of the questionnaire and the observation schedules and the focus group discussions, it was deduced that majority of the teachers strongly agreed that they underutilized conventional instructional resources in the public secondary schools in Bungoma County. Therefore the study schools should encourage an effective utilization of conventional instructional resources to improve on students' classroom performance.

The findings are in line with earlier findings by Ashioya (2012), in a study on factors affecting effective utilization of libraries in secondary schools opined that libraries were not a priority in secondary schools and continued to be neglected as an integral part of education system. Talking about utilization of physical and material resources in teaching and learning, it is important to know that the teacher as the facilitator must have practical knowledge on using these materials when available and improvise when not readily available.

Usman (2007) noted that without the teacher who is knowledgeable, educational material cannot create change and progress. However Kitheka (2005) opined that schools with abundantly conventional resources not always utilize them efficiently and consequently fail to raise student's level of performance. On the other hand schools with limited resources may utilize what they have efficiently and this may boost learning and students should be able to maximize and utilize available resources so as to adequately achieve educational objectives. On the same vein, Obwocha (2005, October 6) described a certain school as 'the sick man of the National schools in K.S.C.E' in spite of possessing adequate facilities and 74 teachers. Similarly, Munyori (2006, March 6) opined that some National schools are a national shame. This is in reference to the poor performance of three schools that tailed in 2005 K.SCE exam in the National schools category according to the results published in the Daily Nation and the Standard newspapers of March 2 2006. This cannot be a better example of the importance of optimum utilization of resources than that of National schools that perform poorly. This is supported by Cohen et al (2003) who opined that out that it is not making resources available to schools that matters, but getting those resources to be used by teachers and students to get academic content learned.

According to Aguolu and Aguolu (2002), opined that resources may be available in the library and even identified bibliographically as relevant to ones subject of interest but the user may not be able to lay hands on them. The more accessible information sources are the more likely they are to be used because readers tend to use information sources that require the least effort to access. This study was necessary to ascertain whether students' utilized conventional resources for effective classroom performance. Larson (2001) quoted Lane (1994) who noted that the use of electronically mediated instructional to duplicate the traditional face to face classroom has resulted in a shift from teacher- to student-centred classes. In this situation the responsibility for learning is shifted to the students. The teacher facilitates the learning by acting as a coach, resource guide and companion in learning.

A study by Altbach (1993) showed that little has ever replaced the printed word as the main element in the educational system and as such textbooks are vital to learning at all levels. According to Owoeye and Yala (2010), in many instances textbooks are the main source of information for both learners and teachers as well as the course work and thus need for more studies on the topic. Squire (1991) reporting on teachers and learners reliance on textbooks asserted that those professional seeking to improve the educational quality of in instructional resources would lead inevitably to changes in actual teaching and learning process. However the selection and acquisition of textbooks has been shown to be of much importance to achievement in academic, it is sad to opine that relevant textbooks are not available for learning and teaching activities.

A study by Ogunwemimo and Odulaja (1989), noted that inadequacy of textbooks was found to be identified with the high cost of textbooks. Since the educational system functions in a world of textbooks according to Owoeye and Yala (2010), asserted that the main purpose of a library in the school was to make books available to the learners at their easy convenience to all periodicals, books and other reproduced resources which are of value and interest are not provided as supplementary and basic textbooks. They further noted that as a resource the libraries occupy a primary and central place in any learning system as it supports all teaching 
functions of the institution. According to Fowowe (1988) the library must be well equipped with current information materials and also allow access to retrospective materials.

During the Amman Mid-Decade Review of education for all (EFA) initiative, attending nations observed that the provision of basic education especially for girls had remained elusive in many less in industrialized countries. This was said to be particularly so in Africa where issues like tensions and conflicts have displaced many households, thus denying children opportunities to schooling. During this conference, member governments focused on the need to mobilize strong national and international political commitment for education for all, including significantly enhanced investments in basic education in provision of teaching and learning resources. Member governments were required to create safe and healthy educational environments conducive for suitable learning materials that would enable learners to attain and surpass well defined levels of educational achievements. There was need to enhance the status, moral and professionalism among teachers.

The study further sought to determine the school principals' opinion on the utilization of conventional resources and students' classroom performance and the findings were as presented in Table 2.

Table 2. Principals' Responses on Extent of Conventional Resource Utilization

\begin{tabular}{llllll}
\hline Availability of Conventional Instructional & \multicolumn{7}{l}{ Responses (Percentage) } & & \\
\cline { 2 - 6 } Resources & $\mathbf{5}$ & $\mathbf{4}$ & $\mathbf{3}$ & $\mathbf{2}$ & $\mathbf{1}$ \\
Usage of facilities in laboratory & $13(16.7)$ & $33(38.9)$ & $8(11.1)$ & $13(16.7)$ & $13(16.7)$ \\
Usage of facilities in library & $17(22.2)$ & $17(22.2)$ & $7(5.6)$ & $13(16.7)$ & $26(33.3)$ \\
Text books & $35(44.4)$ & $13(16.7)$ & $17(22.2)$ & $8(11.1)$ & $7(5.6)$ \\
Usage of resource persons & $7(5.6)$ & $17(22.2)$ & $13(16.7)$ & $35(44.4)$ & $8(11.1)$ \\
Usage of field trips/excursions & $7(5.6)$ & $8(11.1)$ & $22(27.8)$ & $26(33.3)$ & $17(22.2)$ \\
Usage of computers in teaching & $7(5.6)$ & $17(22.2)$ & $13(16.7)$ & $22(27.8)$ & $17(22.2)$ \\
Use of models & $13(16.7)$ & $17(22.2)$ & $26(33.3)$ & $13(16.7)$ & - \\
Usage of internet in teaching & $13(16.7)$ & $17(22.2)$ & $13(16.7)$ & $22(27.8)$ & $13(16.7)$ \\
\hline
\end{tabular}

Legend: 5- strongly agree, 4-agree, 3-neutral, 2-disagree, 1-agree

Table 4.10 showed that principal participants strongly agreed on the use of the following; $35(44.4 \%)$ used textbooks, set books, reference books in teaching and teachers' teaching guides, charts, calculators and teaching aids, are an important requirement for syllabus coverage in preparation for internal and national examinations. They also improved revision and assignment completions. Therefore attainment in academics could not be attained unless there is extensive and proper use of the available books in schools. Only $33(38.9 \%)$ agreed on use of facilities in laboratory as well as facilities in library usage in teaching. These principals' responses indicated that there was a minimal usage of these resources. This opined that learning resources are widely used in learning and teaching in FDSS. The dismal usage of resources in the laboratory, computer room and library may be attributed to the fact that these rooms are equipped poorly and therefore trainers may find them to have little importance in improving the mode of delivery of lessons. Again many schools had put their priorities in acquisition of set books, textbooks and teachers' teaching guides at the expense of other teaching materials. According to Republic of Kenya (2011), secondary schools should have attained textbook to students' ratio of 1:1 by 2012.According to Munyori (2005), teaching and learning materials rank above uniforms, buses and buildings therefore the need for course books in the ratio of 1:1 cannot be overemphasized if learners are to do extra work on their own. This is supported by Mutai (2006) who asserted that learning is strengthened when there are enough reference materials such as textbooks among others. Further, he asserted that the correct use of learning materials enhanced academic achievement. Similarly, a survey conducted by Education Insight (2005) in Kenya revealed that inadequate learning materials and facilities are a common feature in many schools.

The study investigated the extent of use of resource persons. The responses of the principals were 35 $(44.4 \%)$ disagreed on use of resource persons. In schools, resources persons usually included KCSE examiners, motivational speakers and counselors. The examiners equip the learners with skills to answer questions in national examinations while the motivational speakers are largely meant to guide the students on methods of study, developmental challenges, discipline, drug and substance abuse, relationships, among others. Resource persons play a key role in helping schools achieve their goals, in particular academic achievement.

On the extent of use of excursion/field trip the study found out that the responses of the teachers were $26(33.3 \%)$ disagreed on use of field trips and recreational facilities. This could be partly due to the fact that most schools do not have buses; hence excursions would entail hiring some means of transport which would be too expensive. The high cost of fuel witnessed in the past few years is also making travelling expensive even for those schools that own buses or vans. Excursions and field trips involve a lot of time in terms of preparation and actual study which may interfere with the formal school timetable. Excursions and field trips enhance learning because they make classroom learning real and break monotony and create interest. This agrees with the findings of Oyeniran (2003) who observed that students learn best if they are given the opportunity to see and to make observation of what they are taught. 
Based on the teachers and principals opinions on their utilization of conventional resources in the study schools it was observed that it is clear that conventional instructional resources is a fruitful and worthy program in enhancing students' classroom performances. From the study objective it's also clear that conventional resources are fairly utilized, except text books. An analysis of utilization of conventional resources shows an over stretch. Both principals and teachers further indicated that the usage of laboratories and library facilities was inadequate that newly employed teachers embraced the use of library materials as compared to their old and more experienced counterparts. The study also showed that the usage of computers and the internet was very low; however most teachers aged below 40 years used the available computers and internet connectivity to enhance students' e-learning.

\subsubsection{CONCLUSION}

It was conclude that majority of the students asserted that their teachers had frequently assigned them with both class and take away assignments and this enhanced their utilization of the available conventional resources. The study also deduced that deduced that the level of students' utilization of conventional instructional resources was below the average mean as deduced from the principals from the public secondary schools in Bungoma County. The analysis of the questionnaire showed that majority of principals agreed that students' utilization of textbooks, teachers' guides, laboratories, and resource persons in public secondary schools in Bungoma County was below average and therefore a unit increase in the utilization of resource persons could improve students' classroom performance. The study also indicated that most of the principals were in agreement that students' utilization of the library services, computers, teaching aids, video tape recorders, radio during classroom instructional and students' usage of the internet content in the study schools was below the average mean. The study also deduced that there was a significant relationship between teacher training and students' classroom performance as indicated by a beta coefficient $(\beta 2)$ of 0.925 , however there was a weak relationship between quality teaching with beta coefficient $(\beta 2)$ of 0.288 , guidance with beta coefficient $(\beta 2)$ of 0.145 and teacher commitment with beta coefficient $(\beta 2)$ of 0.177 and students' classroom performance while there was a negative relationship between teaching facilities with beta coefficient $(\beta 2)$ of -0.113 , teacher/student ratio with a beta coefficient $(\beta 2)$ of -0.048 and student book ratio with beta coefficient $(\beta 2)$ of -0.383 and students' classroom performance in public secondary schools in Bungoma County. Therefore teacher training directly influenced students' classroom performance in the study schools.

\section{RECOMMENDATIONS}

It was recommendations principals and officials of the Ministry of Education should ensure regular supervision to enhance effective use of conventional instructional materials and resources in enhancement of classroom performance in public secondary schools in Bungoma County. TSC should employ more teachers to cater for the enormous teacher shortage, in service training programs should also be initiated to address manpower needs as a result of changing times to enable teachers embrace use and access to computers and the internet and provision of e-materials. Where the internet is unavailable, unreliable or unaffordable, the development of local school networks and the provision of e-materials to schools on compact disks (CDs/ flash disks) can support e-learning via school servers and networks.

\section{REFERENCES}

Shiundu, J. and Omulando (1992) curriculum theory and practice in Kenya, Nairobi oxford University Press Maicibi N. (2003), human resource management success, Kampala net media Publication ltd. Uganda.

Borufreund L. (2011). Do teachers care about pay? Yes, but not as much as you think.Factors causing teachers to leave. 2(1)115-125

Parrot E. (1982), effective teaching, a practical guide to improving your teaching,Longman, New York

Kwesiga S. (2002), Women; access to higher education, fifteen years on PCP Publishing limited.

Oluoch G. (1982) Essentials of curriculum foundations, Principals and issues London Allyn and Bacon

Cohen D. (2002) Resources, instructional and research. In Mosteller and Boruch (Eds),Evidence matters, Washington D.C Brookings Institute Press.

Otunga R. (2001). A handbook of curriculum and instruction, Moi university press Eldoret Kenya. 